\title{
Backward Pumped Fiber Raman Amplifiers Gain Enhancement
}

\section{Abd Elbaki ${ }^{1}$, Mustafa FM $^{2 *}$ and Barakat TM ${ }^{2}$}

${ }^{1}$ Electrical Engineering Department, Faculty of Engineering, Fayoum University, Fayoum, Egypt

${ }^{2}$ Electrical Engineering Department, Faculty of Engineering, Beni-Suef University, Beni-Suef, Egypt

\begin{abstract}
Raman Amplifiers (RAs) are a group of amplifiers which have various applications in optical communications. Data transmission media utilized for RAs are optical fibers operating in nonlinear regime. We present the performances and characteristics of RAs by utilizing a set of coupled differential equations and numerical simulations. The purpose of this paper is to simulate and analyze the parameters affecting on Raman gain for all optical backward pumped fiber Raman amplifier such as fiber type, fiber length, pump power and gain coefficient for enhancement the gain of fiber Raman amplifier. Three types of fibers with different gain characteristics are used in our numerical simulations. So, the optimum initial values of the pump powers for a system with three pumps are recalculated and optimized again.
\end{abstract}

Keywords: Raman amplifiers; Distributed Raman amplifier; Pump power and gain coefficient

\section{Introduction}

The rapid revolution of communications in the last few years has opened the field of research on optical communication and placed it on research objectives in communications engineering, and also the broad features of optical networks make it as back bone communication systems. One solution to renew the signal is to convert the optical signal to the electric field and then convert it back to a new optical signal. However, pure optical amplifiers are usually preferred [1]. When the Raman pump wave has slight random power fluctuations in time, it is almost the case, individual bits, differential amplification, which can lead to capacitance fluctuations or jitter. If the rear pump is applied, the average voltages in amplitude [2] will be calculated. Raman fiber amplifiers are now used all Raman or hybrid FRAs/EDFAs at both long distances and very long wavelength wavelengths divided by multiplex optical communication systems [3]. Optical amplifiers are essential elements of any fiber optic communication system. Although modern optical fibers have losses below $0.2 \mathrm{~dB} / \mathrm{km}$, the repeated amplification of the signal sent to its original power becomes necessary at sufficiently long distances. One solution to renew the signal is to convert the optical signal into the electric field and then convert it back to a new optical signal [4]. However, it is recommended that the amplification on the optical field be considered as conversion time, noise resulting from the conversion process, cost and reliability. Therefore, the optical amplifiers have advanced rank. It can help design optical transmission system issues such as mid-distance visually amplify, and enhance bandwidth using Raman optical amplification (ROA) technology. ROA does not suffer from EDFA limitations in that it can be integrated with transmission fibers, and is pumped at any wavelength to provide wide gain bandwidth and gain flatness by using a combination of different wavelength pumping sources. Raman amplifier is based on Raman scattering motif phenomena (SIRS) is a nonlinear optical process in which the photon is absorbed and called the photon pump by the material while simultaneously emit a photon of different energy. The difference in photon energy is compensated by changing the vibrational state of the substance [5]. There are two Raman speakers: a separate Raman amplifier and a Raman amplifier (DRA) distributed. The distributed fiber optic type is used as an active medium. If the amplifier is included in the box at the end of the transmitter or receiver of the system, it will call a separate Raman amplifier [6]. One of the most commonly used in contemporary submarines and long-distance terrestrial networks is the distributed Raman Amplifier (DRA), where
Raman amplification can occur in any fiber at any signal wavelength by proper selection of the pump wavelength. The Raman gain process is very fast [7]. This paper presented two optical amplifiers in cascaded form to enhancement the gain of the amplifier the first is forward pump amplifier and the second is backward pump amplifier, also we simulate and analyze the parameters affecting on Raman gain of fiber Raman amplifier for three different fiber types.

\section{Model and Equations Analysis}

The scheme of a typical DRA which uses two Raman fiber amplifiers the first forward pump Raman amplifier and the second is feedback pump Raman amplifier in cascaded form to enhancement the Raman gain of feedback Raman amplifier is shown on Figure 1. When the

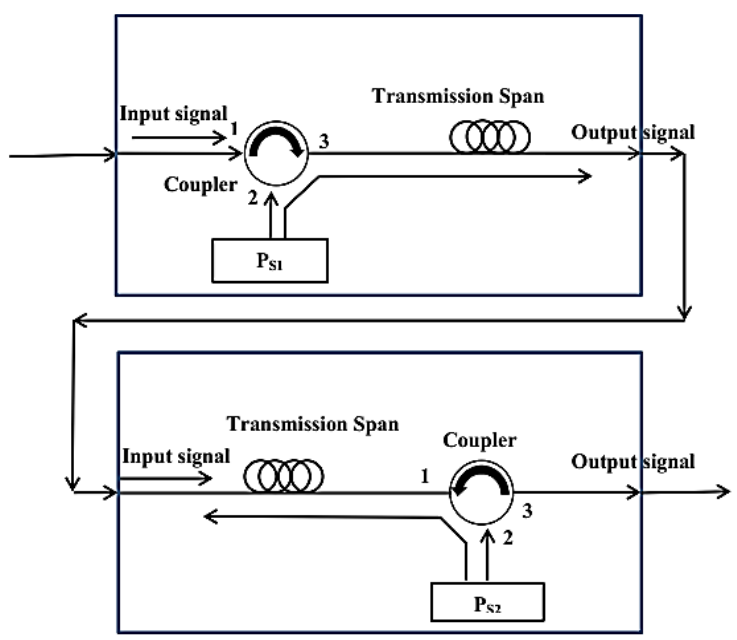

Figure 1: Design model of Raman amplifier system scheme.

*Corresponding author: Mustafa FM, Electrical Engineering Department, Faculty of Engineering, Fayoum University, Fayoum, Egypt; E-mail: Fmmg80@eng.bsu.edu.eg

Received May 15, 2018; Accepted May 28, 2018; Published June 06, 2018

Citation: Elbaki A, Mustafa FM, Barakat TM (2018) Backward Pumped Fiber Raman Amplifiers Gain Enhancement. J Telecommun Syst Manage 7: 160. doi: 10.4172/2167-0919.1000160

Copyright: @ 2018 Elbaki A, et al. This is an open-access article distributed under the terms of the Creative Commons Attribution License, which permits unrestricted use, distribution, and reproduction in any medium, provided the original author and source are credited. 
pump power propagates in the direction of the signal, it is called co- or forward pumping scheme, and when the pump travels in the opposite direction, it is called counter or backward pumping. The pump sources marked as $\mathrm{P}_{\mathrm{S} 1}$ and $\mathrm{P}_{\mathrm{S} 2}$ are placed at both ends of the transmission span and their power are switched in the medium of the silica fiber using optical couplers [8].

The fiber signal propagates in fiber media with the power signal according a couple of differential equation, this equation describe not only the signals attenuation due to propagation but also the power transfer from the power signal as follow [9-11]:

$$
\begin{aligned}
& \pm \frac{\partial \mathrm{P}_{p}}{\partial \mathrm{Z}}=-\frac{\omega_{p}}{\omega_{s}} G_{R} P_{p} P_{s}-\alpha_{p} P_{p} \\
& \frac{\partial \mathrm{P}_{s}}{\partial \mathrm{Z}}=G_{R} P_{p} P_{s}-\alpha_{s} P_{s}
\end{aligned}
$$

where $\mathrm{G}_{\mathrm{R}}$ is the Raman gain coefficient related to the fiber type $\left(\mathrm{W}^{-1} \cdot \mathrm{m}^{-1}\right)$, $\alpha_{s}$ and $\alpha_{p}$ are the attenuation coefficient related to the optical signal and the pumping power in same order, $\omega_{\mathrm{s}}$ and $\omega_{\mathrm{p}}$ are the angular frequency related to the optical signal and the pumping power in same order [12].

Therefore to calculate the pump power at point $\mathrm{z}$ it can be used:

$$
\mathrm{P}_{\mathrm{p}}(\mathrm{Z})=\mathrm{SP}_{\mathrm{p}}(0) \cdot \mathrm{e}^{-\alpha_{\mathrm{p}} Z(1-\mathrm{s})}=\mathrm{P}_{\mathrm{p}}(0) \cdot \mathrm{e}^{-\alpha_{\mathrm{p}}(L-Z)}
$$

If the values of $\mathrm{P}_{\mathrm{p}}$ are substituted in differential eqn. (2), and it is integrated from 0 to $\mathrm{L}$ for the signal power in the forward and the backward pumping, it can be written as [13-15]:

$$
\begin{aligned}
& P_{s}(Z)=P_{s}(0) \cdot e^{\left(G_{R} P_{0}\left(\frac{\left(1-\exp \left(-\alpha_{\mathrm{p}} \mathrm{Z}\right)\right)}{\alpha_{\mathrm{p}}}\right)-\alpha_{\mathrm{s}} \mathrm{Z}\right)}=\mathrm{G}_{\mathrm{F}} \cdot \mathrm{P}_{\mathrm{s}}(0) \\
& \mathrm{P}_{\mathrm{s}}(\mathrm{Z})=\mathrm{P}_{\mathrm{s}}(0) \cdot \mathrm{e}^{\left(\mathrm{G}_{\mathrm{R}} \mathrm{P}_{\mathrm{o}}\left(\frac{\exp \left(-\alpha_{\mathrm{p}} \mathrm{L}\right)\left(1-\exp \left(-\alpha_{\mathrm{p}} \mathrm{Z}\right)\right)}{\alpha_{\mathrm{p}}}\right)-\alpha_{\mathrm{s}} \mathrm{Z}\right)}=\mathrm{G}_{\mathrm{B}} \cdot \mathrm{P}_{\mathrm{s}}(0)^{\prime}
\end{aligned}
$$

where $G_{F}, G_{B}$ are the net gain in the forward and backward pumping respectively. With $P_{O}$ being the pump power at the input end, $\alpha_{S}$ and $\alpha_{P}$ are the linear attenuation coefficient of the signal and pump power in the optical fiber respectively, can be expressed as $[16,17]$ :

$$
\alpha_{S, P}=\alpha / 4.343 \text {, }
$$

where $\alpha$ is the attenuation coefficient in $\mathrm{dB} / \mathrm{km}$.

From eqns. (4) and (5) we can get the total gain of fiber Raman amplifier due to using forward pump Raman amplifier and feedback pump Raman amplifier in cascaded form to enhancement the Raman gain of feedback Raman amplifier can be expressed as:

$$
\mathrm{G}_{\mathrm{T}}=\mathrm{G}_{\mathrm{F}} \times \mathrm{G}_{\mathrm{B}}
$$

Where, $G_{t}$ the total gain of forward pump Raman amplifier and feedback pump Raman amplifier then,

$$
\begin{aligned}
& G_{T}=\exp \left[\mathrm{g}_{\mathrm{R}} P_{0} x \frac{\exp \left(-\alpha_{P} L\right)\left(\exp \left(\alpha_{P} z\right)-1\right)}{\alpha_{P}}-\alpha_{S} Z\right] \times \exp \left[\mathrm{g}_{\mathrm{R}} P_{0} x \frac{1-\exp \left(-\alpha_{P} z\right)}{\alpha_{P}}-\alpha_{S} Z\right] \\
& G_{T}=\exp \left[\mathrm{g}_{\mathrm{R}} P_{0} x \frac{\exp \left(-\alpha_{P} L\right)\left(\exp \left(\alpha_{P} z\right)-1\right)}{\alpha_{P}}+\mathrm{g}_{\mathrm{R}} P_{0} x \frac{1-\exp \left(-\alpha_{P} z\right)}{\alpha_{P}}-2 \alpha_{S} Z\right] \\
& G_{T}=\exp \left[\mathrm{g}_{\mathrm{R}} P_{0} x \frac{\mathrm{a}-b-c}{\alpha_{P}}-2 \alpha_{S} Z\right]
\end{aligned}
$$

Where;

$$
a=\exp \left(-\alpha_{\mathrm{P}} L\right) \cdot \exp \left(\alpha_{\mathrm{P}} \mathrm{z}\right), \mathrm{b}=\exp \left(-\alpha_{\mathrm{P}} \mathrm{L}\right) \text { and } \mathrm{c}=\exp (-\alpha \mathrm{P} Z)
$$

The signal intensity at output of amplifier, fiber cable length $L$ is determined by the following expression [18]:

$$
P_{s}(L)=P_{s}(0) \exp \left(\frac{g_{0} P_{0} L}{A_{e f f}}-\alpha_{s} L\right)
$$

The effective length, $\mathrm{L}_{\text {eff }}$ is the length over which the nonlinearities still holds or stimulated Raman Scattering (SRS) occurs in the fiber and is defined as:

$$
\mathrm{L}_{\text {eff }}=\frac{1-\exp \left(-\alpha_{\mathrm{p}} \mathrm{L}\right)}{\alpha_{\mathrm{p}}}
$$

Hence the amplification gain defined as the ratio of the power signal with and without Raman amplification, is given by the following expression [19]:

$$
G_{A}=\frac{P_{S}}{P_{S}(0) \exp \left(-\alpha_{s} L\right)}
$$

\section{Results and Discussion}

In this section the result simulated by using of two Raman fiber amplifiers the first forward pump Raman amplifier and the second is feedback pump Raman amplifier in cascaded form to enhancement the Raman gain of feedback Raman amplifier, where for backward Raman amplifier only the gain is attenuated from input signal power to intersect the zero axis or reach to zero and continues to negative part then reflect to increase to reach maximum value at fiber length spam, but in this case gain is start to increasing from zero to indicated value of Raman gain due to using forward pump Raman amplifier then the gain is attenuated slowly but doesn't reach to zero gain then occurs reflection to the gain to reach maximum value at final spam fiber length.

\section{Relation between Raman Gain and Fiber Length at different pumping power}

In this section we show, the variation of gain with fiber length for different pump powers 800,1000 and $1200 \mathrm{~mW}$ are given for a $100 \mathrm{~km}$ fiber length. As it is shown below for the three different fiber types (SMF, Freelight and Truewave) having different Raman gain coefficients and constant signal input power.

Relation between Raman gain and fiber length at different pumping power for SMS fiber type: Figure 2 shows the relation between Raman gain and fiber length for three different pump powers.

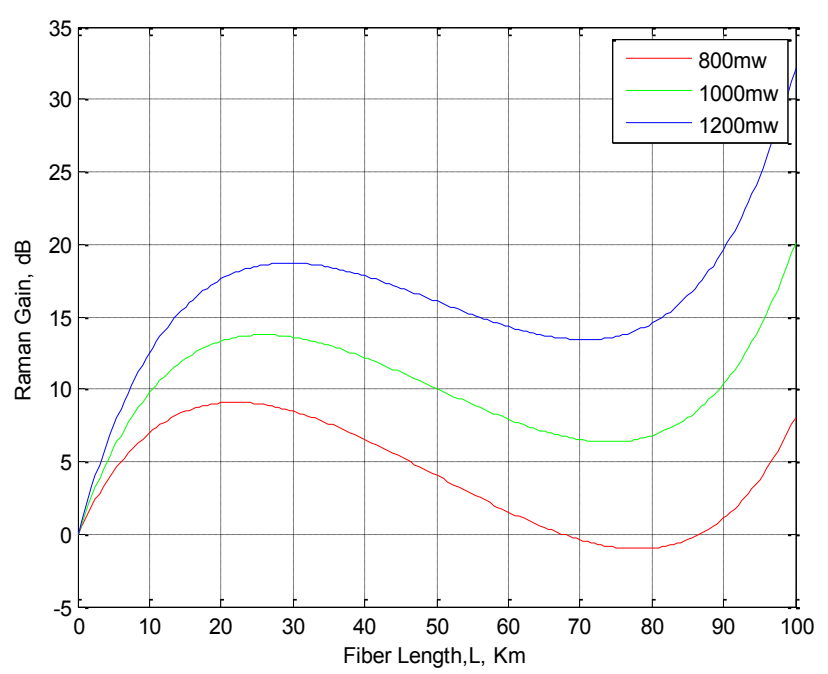

Figure 2: Raman gain against the fiber length with different pumping power for SMF. 
This result simulated by using of two Raman fiber amplifiers the first forward pump Raman amplifier and the second is feedback pump Raman amplifier in cascaded form to enhancement the Raman gain of feedback Raman amplifier, where for backward Raman amplifier only the gain is attenuated from input signal power to intersect the zero axis or reach to zero and continues to negative part then reflect to increase to reach maximum value at fiber length spam as shown in previous results, but in this case gain is start to increasing from zero to indicated value of Raman gain as shown in Figure 2 due to using forward pump Raman amplifier then the gain is attenuated slowly but doesn't reach to zero gain then occurs reflection to the gain to reach maximum value at final spam fiber length. This achieved by using high pumping power up to $800 \mathrm{~mW}$.

Relation between Raman gain and fiber length at different pumping power for Freelight fiber type: Figure 3 shows the obtained gain from a model amplifier at different pump powers. As shows Figure 3 , gain is start to increasing from zero to indicated value of Raman gain due to using forward pump Raman amplifier then the gain is attenuated slowly but doesn't reach to zero gain then occurs reflection to the gain to reach maximum value at final spam fiber length. This achieved by using high pumping power as shown in Figure 3 . Then we concluded that we must be increase the pumping power levels to reduced attenuation and increases the gain of the amplifier and in this case the gain doesn't reach to zero gain also this results give the Freelight fiber type is the most powerful Raman amplification media than SMS fiber type this is because of large Raman gain coefficient and low power signal attenuation. Also, in case of $1000 \mathrm{~mW}$ pumping power is better than in case of $800 \mathrm{~mW}$ pumping power.

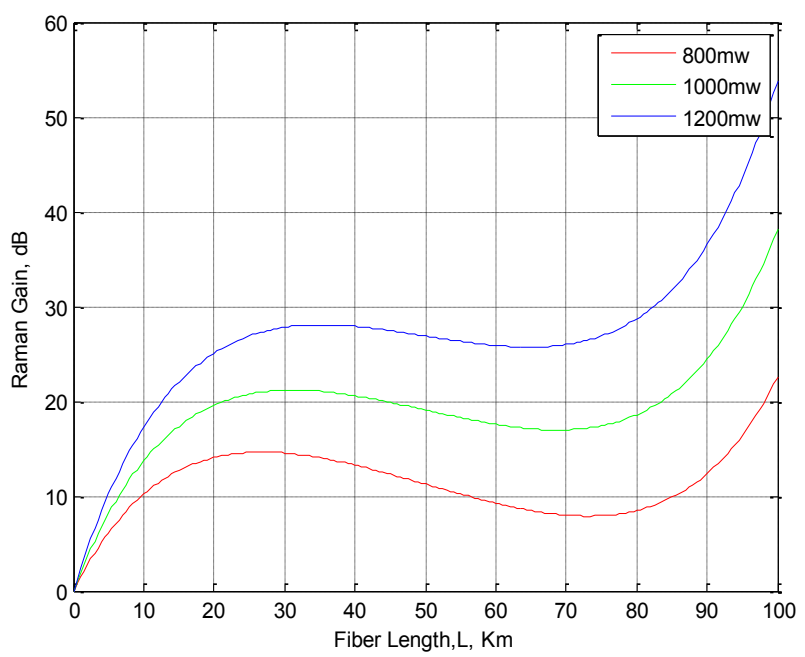

Figure 3: Raman gain against the fiber length with different pumping power for Freelight.

Relation between Raman gain and fiber length at different pumping power for Truewave fiber type: Figure 4 shows the obtained gain from a model amplifier at different pump powers. Also as shows Figure 4, gain is start to increasing from zero to indicate value of Raman gain due to using forward pump Raman amplifier then the gain is saturated from $30 \mathrm{~km}$ to $70 \mathrm{~km}$ then gain is start to increasing to reach maximum value at final spam fiber length. This results give the Truewave fiber type is the most powerful Raman amplification media than the other two types this is because of large Raman gain coefficient and low power signal attenuation. Also, in case of $1200 \mathrm{~mW}$ pumping power is better than in case of 800 and $1000 \mathrm{~mW}$ pumping power.

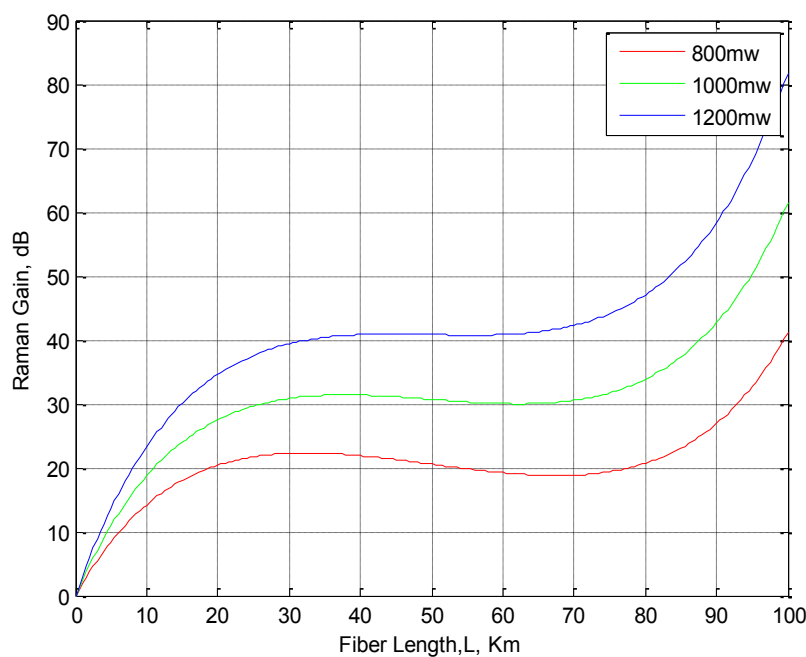

Figure 4: Raman gain against the fiber length with different pumping power for Truewave.

\section{Relation between Raman gain and fiber length for different fiber types}

In this section we show, the variation of gain with fiber length for the three different fiber types (SMF, Freelight and Truewave) having different Raman gain coefficients and constant signal input power and different constant pump powers ( $800 \mathrm{~mW}, 1000 \mathrm{~mW}$ and $1200 \mathrm{~mW})$.

Relation between Raman gain and fiber length for different fiber types at $800 \mathrm{~mW}$ pumping power: Figure 5; show a comparison between three different fiber types (SMF, Freelight and Truewave) at $800 \mathrm{~mW}$ pumping power for the fiber types having different Raman gain coefficients and constant signal input power.

This result simulated by using of two amplifiers the first forward pump Raman amplifier and the second is feedback pump Raman amplifier in cascaded form to enhancement the Raman gain of feedback Raman amplifier, where for backward Raman amplifier only the gain is attenuated from input signal to intersect the zero axis or reach to zero and continues to negative part the reflect to increase to reach maximum value at fiber length spam as shown in previous results , but in this case gain is start to increasing from zero to indicated value of Raman gain as shown in Figure 2 due to using forward pump Raman amplifier then the gain is attenuated slowly but doesn't reach to zero gain then occurs reflection to the gain to reach maximum value at final spam fiber length. This achieved by using high pumping power up to $800 \mathrm{~mW}$ as shown in Figure 5. This results give the Truewave fiber type is the most powerful Raman amplification media than the other two types this is because of large Raman gain coefficient and low power signal attenuation.

Relation between Raman gain and fiber length for different fiber types at $1000 \mathrm{~mW}$ pumping power: Figure 6; show a comparison between three different fiber types (SMF, Freelight and Truewave) at $1000 \mathrm{~mW}$ pumping power for the fiber types having different Raman gain coefficients and constant signal input power.

Form Figure 3, we get gain is start to increasing from zero to indicated value of Raman gain due to using forward pump Raman amplifier then the gain is attenuated slowly but doesn't reach to zero gain then occurs reflection to the gain to reach maximum value at final spam fiber length. This achieved by using high pumping power 


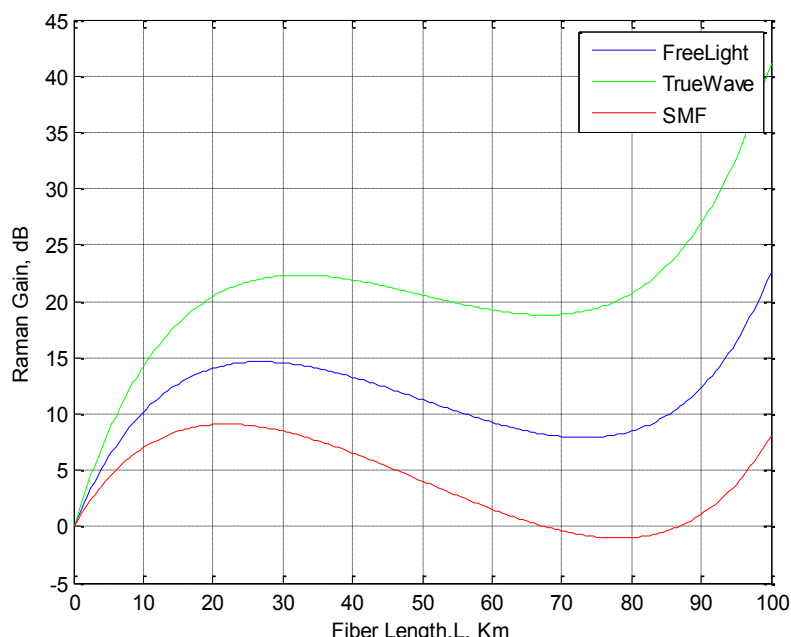

Figure 5: Raman gain against the fiber length with different fiber types at 800 mW pumping power.

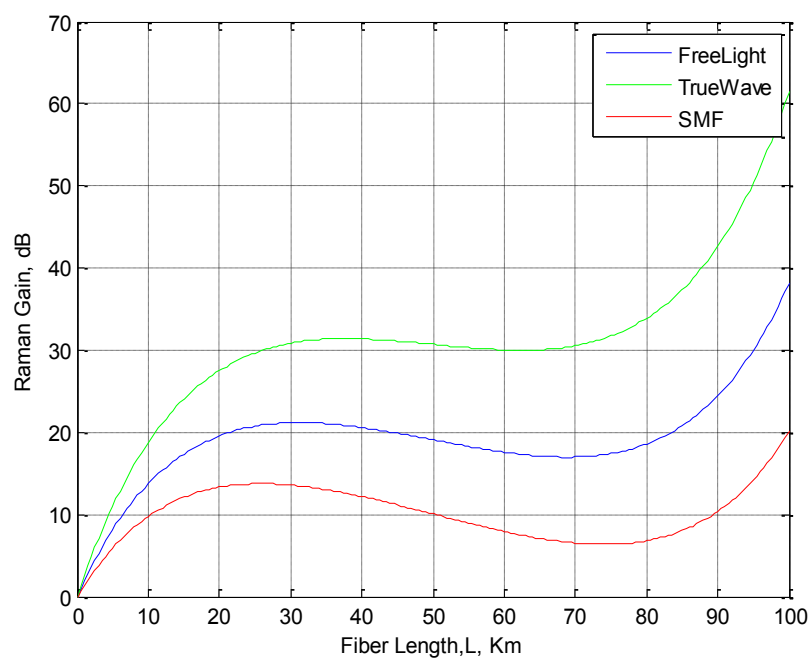

Figure 6: Raman gain against the fiber length with different fiber types at 1000 mW pumping power.

as shown in Figure 3. Then we concluded that we must be increase the pumping power levels to reduced attenuation and increases the gain of the amplifier and in this case the gain doesn't reach to zero gain. This results give the true wave fiber type is the most powerful Raman amplification media than the other two types this is because of large Raman gain coefficient and low power signal attenuation.

Also, in case of $1000 \mathrm{~mW}$ pumping power is better than in case of $800 \mathrm{~mW}$ pumping power.

Relation between Raman gain and fiber length for different fiber types at $1200 \mathrm{~mW}$ pumping power: Figure 7; show a comparison between three different fiber types (SMF, Freelight and Truewave) at $1200 \mathrm{~mW}$ pumping power for the fiber types having different Raman gain coefficients and constant signal input power.

As shows Figure 7, gain is start to increasing from zero to indicate value of Raman gain due to using forward pump Raman amplifier then the gain is saturated from $30 \mathrm{~km}$ to $70 \mathrm{~km}$ then gain is start to increasing to reach maximum value at final spam fiber length. This results give the
Truewave fiber type is the most powerful Raman amplification media than the other two types this is because of large Raman gain coefficient and low power signal attenuation. Also, in case of $1200 \mathrm{~mW}$ pumping power is better than in case of $1000 \mathrm{~mW}$ pumping power and $800 \mathrm{~mW}$ pumping power, then we get the attenuation in the gain is reduced by increasing the pump power but the gain is increases.

\section{Output signal power characteristics for backward pumping}

This section show how the output signal power varies with the fiber length for different pump powers and fiber span of $100 \mathrm{~km}$ at a constant signal power, $-3 \mathrm{dBm}$, applied to the three fiber types.

Output signal power characteristics for backward pumping at $800 \mathrm{~mW}$ pump power: Figure 8; show the output signal power against fiber length at pump power $800 \mathrm{~mW}$ and constant signal power, -3 $\mathrm{dBm}$, applied to the three fiber types.

Figure 8; was simulating the $-3 \mathrm{dBm}$ of input signal along $100 \mathrm{~km}$ of fiber span and $400 \mathrm{~mW}$ of pumping power in three different fiber types

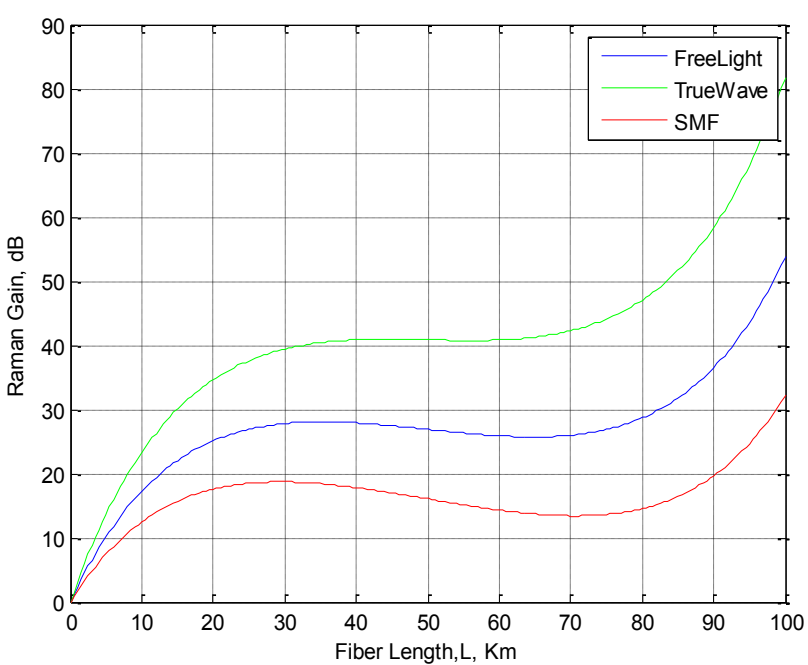

Figure 7: Raman gain against the fiber length with different fiber types at 1200 $\mathrm{mW}$ pumping power.

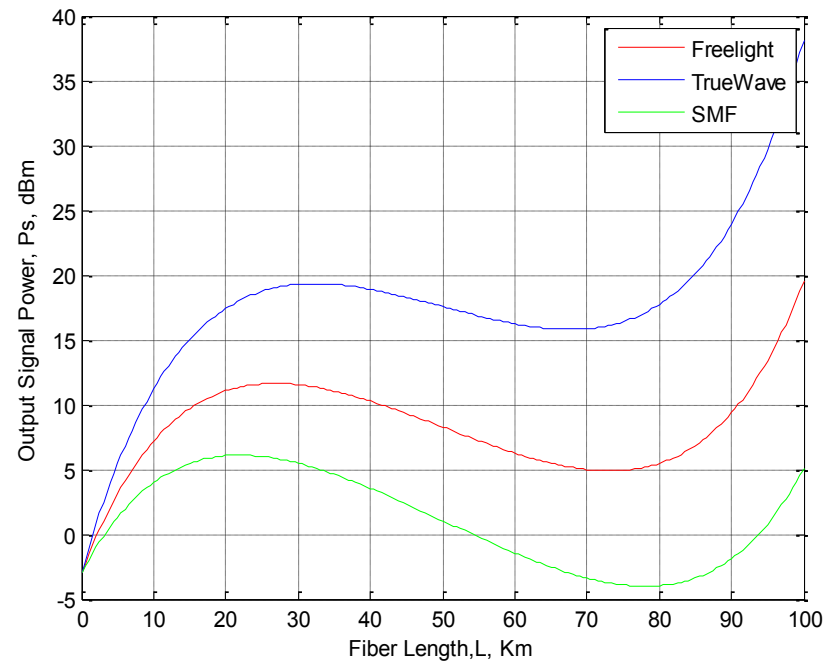

Figure 8: Output signal power against fiber length at $800 \mathrm{~mW}$ pumping powe and $-3 \mathrm{dBm}$ input signal power. 
in case of SMS fiber type the output signal power is start to increasing from zero to indicated value of output signal power as shown in Figure 8 , due to using forward pump Raman amplifier then the output signal power is attenuated slowly to reach zero then occurs reflection to the output signal power at $80 \mathrm{~km}$ fiber length to reach maximum value at final spam fiber length. But in case of Ferrlight the output signal power is start to increasing from zero to indicated value of output signal power as shown in Figure 8, due to using forward pump Raman amplifier then the output signal power is attenuated slowly but doesn't reach to zero then occurs reflection to the output signal power to reach maximum value at final spam fiber length. and in case of Truewave fiber the output signal power is start to increasing from zero to indicated value of output signal power as shown in Figure 8, due to using forward pump Raman amplifier then the output signal power is attenuated slowly then occurs reflection to the output signal power to reach maximum value at final spam fiber length. After simulation the output signal power for different fiber types along $100 \mathrm{~km}$ of fiber span and $800 \mathrm{~mW}$ pumping power this results give the Truewave fiber type is the most powerful output signal power media than the other two types this is because of large Raman gain coefficient and low power signal attenuation.

Output signal power characteristics for backward pumping at $1000 \mathrm{~mW}$ pump power: Figure 9; show the output signal power against fiber length at pump power $1000 \mathrm{~mW}$ and constant signal power, -3 $\mathrm{dBm}$, applied to the three fiber types.

From Figure 9, we get the output signal power is start to increasing from zero to indicated value of output signal power due to using forward pump Raman amplifier then the output signal power is attenuated slowly but doesn't reach to zero gain then occurs reflection to the output signal power at $70 \mathrm{~km}$ fiber length to reach maximum value at final spam fiber length. But in case of Ferrlight output signal power is start to increasing from zero to indicated value of output signal power due to using forward pump Raman amplifier then the output signal power is attenuated slowly then occurs reflection to the output signal power at $70 \mathrm{~km}$ fiber length to reach maximum value at final spam fiber length and in case of Truewave fiber the output signal power behave the same way of SMS and Freelight but output signal power is very high (is the best one).

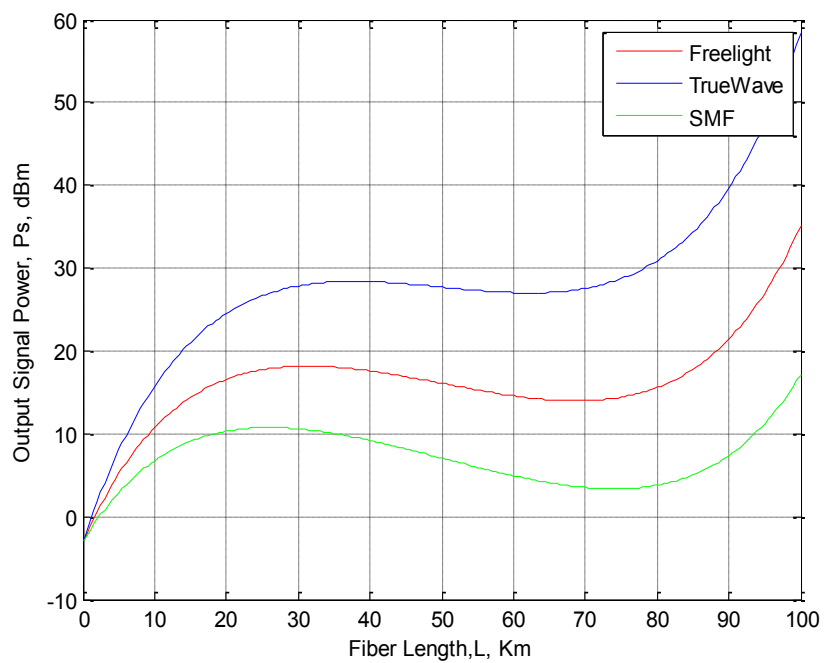

Figure 9: Output signal power against fiber length at $1000 \mathrm{~mW}$ pumping power and $-3 \mathrm{dBm}$ input signal power.

After simulation the output signal power for different fiber types along $100 \mathrm{~km}$ of fiber span and $1000 \mathrm{~mW}$ pumping power this results give the Truewave fiber type is the most powerful output signal power media than the other two types this is because of large Raman gain coefficient and low power signal attenuation.

Output signal power characteristics for backward pumping at $\mathbf{1 2 0 0} \mathrm{mW}$ pump power: Figure 10; show the output signal power against fiber length at pump power $1200 \mathrm{~mW}$ and constant signal power, $-3 \mathrm{dBm}$, applied to the three fiber types.

The result in Figure 10, show output signal power is start to increasing from zero to indicate value of output signal power due to using forward pump Raman amplifier then the output signal power is saturated from $30 \mathrm{~km}$ to $70 \mathrm{~km}$ then output signal power is start to increasing to reach maximum value at final spam fiber length. This results give the Truewave fiber type is the most powerful Raman amplification media than the other two types this is because of large Raman gain coefficient and low power signal attenuation. Also, in case of $1200 \mathrm{~mW}$ pumping power is better than in case of $1000 \mathrm{~mW}$ pumping power and $800 \mathrm{~mW}$ pumping power, then we get the attenuation in the output signal power is reduced by increasing the pump power but the output signal power is increases.

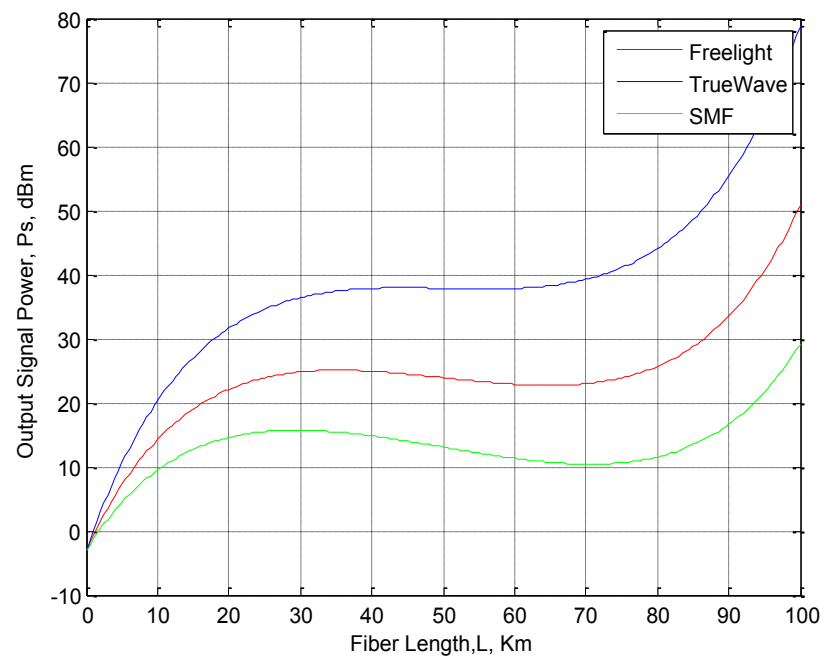

Figure 10: Output signal power against fiber length at $1200 \mathrm{~mW}$ pumping power and $-3 \mathrm{dBm}$ input signal power.

\section{Conclusion}

Simulation results gives enhancement the gain of the amplifier, also we simulate and analyze the parameters affecting on Raman gain of fiber Raman amplifier for three different fiber types. The Raman gain of an optical signal is observed to depend on the selection of pump power. The FRA gain is obtained as a function of fiber length and pump power. According to the obtained results, gain is strongly dependent on the fiber length and pumping power. The differences between three different fiber types are satisfied.

\section{References}

1. Mohammed AAE, Rashed ANZ (2010) Comparison performance evolution of different transmission techniques with bi-directional distributed Raman gain amplification technique in high capacity optical networks. Journal of Electrical and Electronics Engineering Research 2: 95-106.

2. Fugihara MC, Pinto AN (2008) Low-Cost Raman Amplifier for CWDM Systems Microwave and Optical Technology Letters 50: 297-301.

3. Jyoti Dhir E, Vivek Gupta E (2013) Improvement of Gain with Figure of Merit in Discrete Raman Amplifier. International Journal of Computer Science and Communication Engineering 22-24. 
Citation: Elbaki A, Mustafa FM, Barakat TM (2018) Backward Pumped Fiber Raman Amplifiers Gain Enhancement. J Telecommun Syst Manage 7: 160. doi: $10.4172 / 2167-0919.1000160$

4. Zaki Rashed AN (2011) New trends of forward fiber Raman amplification for dense wavelength division multiplexing (DWDM) photonic communication networks. International Journal on Technical and Physical Problems of Engineering 3: 30-39.

5. Dhir J, Gupta V (2014) Improvement of Raman Gain with Different Parameters in Discrete Raman Amplifier. International Journal of Engineering Research and Applications (IJERA)

6. Beshr AH, Aly MH, AboulSeoud2 AK (2012) Amplified Spontaneous Emission Noise Power in Distributed Raman Amplifiers. International Journal of Scientific \& Engineering Research.

7. Anwar NM, Aly MH (2010) Backward Pumped Distributed Fiber Raman Amplifiers, 27th National Radio Science Conference.

8. Toeima AH, Aly MH (2009) Gain and Noise Performance of Fiber Raman Amplifiers, 5th International Computer Engineering Conference.

9. Zaki Rashed AN (2011) New Trends of Forward Fiber Raman Amplification for Dense Wavelength Division Multiplexing (DWDM) Photonic Communication Networks. International Journal of Soft Computing 6: 26-32.

10. Felinsky GS, Korotkov PA (2008) Raman Threshold and Optical Gain Bandwidth in Silica Fibers. Journal of Semiconductor Physics, Quantum Electronics, and Optoelectronics 11: 360-363.

11. Jordanova LT, Topchiev VI (2008) Improvement of the Optical Channel Noise Characteristics using Distributed Raman Amplifiers, ICEST 12: 20-23.

12. EL-Halawany MME (2011) Efficient Raman Amplifiers within Propagation and
Multiplexing Techniques for High Capacity and Ultra Long Haul Transmission Systems. International Journal of Computer Science and Telecommunications, 2: $16-24$.

13. Dhir EJ, Gupta EV (2013) Improvement of Gain with Figure of Merit in Discrete Raman Amplifier. International Journal of Computer Science and Communication Engineering, (IJCSCE), 22-24

14. Singh $P$ (2014) Analysis of Noise Figure of Fiber Raman Amplifier. International Journal of Science and Research (IJSR), 3: 997-999

15. Abd El-Naser AM, Zaki Rashed AN, Eid MMA (2012) High Performance Efficiency of Distributed Optical Fiber Raman Amplifiers for Different Pumping Configurations in Different Fiber Cable Schemes. International Journal of Computer Science and Network (IJCSN).

16. Makoui S, Savadi-Oskouei M, Rostami A, Koozehkanani ZD (2009) Dispersion Flattened Optical Fiber Design for Large Bandwidth and High Speed Optical Communications Using Optimization Technique. Progress In Electromagnetics Research B, 13: 21-40.

17. Mashade MBE, Nady M (2009) Analysis of Ultra Short Pulse Propagation in Nonlinear Optical Fiber. Progress In Electromagnetics Research B 12: 219-241.

18. Mohammed AA, Zaki Rashed AN (2013) Efficient distributed Raman gain amplification technique in modern metro passive optical networks. International Journal of Academic Library and Information Science 1: 10-23.

19. Wasfi M (2009) Optical Fiber Amplifiers Review. International Journal of Communication Networks and Information Security (IJCNIS) 1: 42-47. 